\title{
EVALUATION OF A SOFTWARE PROGRAM FOR STORING, COMPUTING, AND REPORTING CONCRETE TEST RESULTS
}

\author{
by \\ Roy L. Campbell \\ Structures Laboratory \\ DEPARTMENT OF THE ARMY \\ Waterways Experiment Station, Corps of Engineers \\ 3909 Halls Ferry Road, Vicksburg, Mississippi 39180-6199

\section{US-CE-C PROPERTY OF THE UNITED STATES GOVERMMENT}
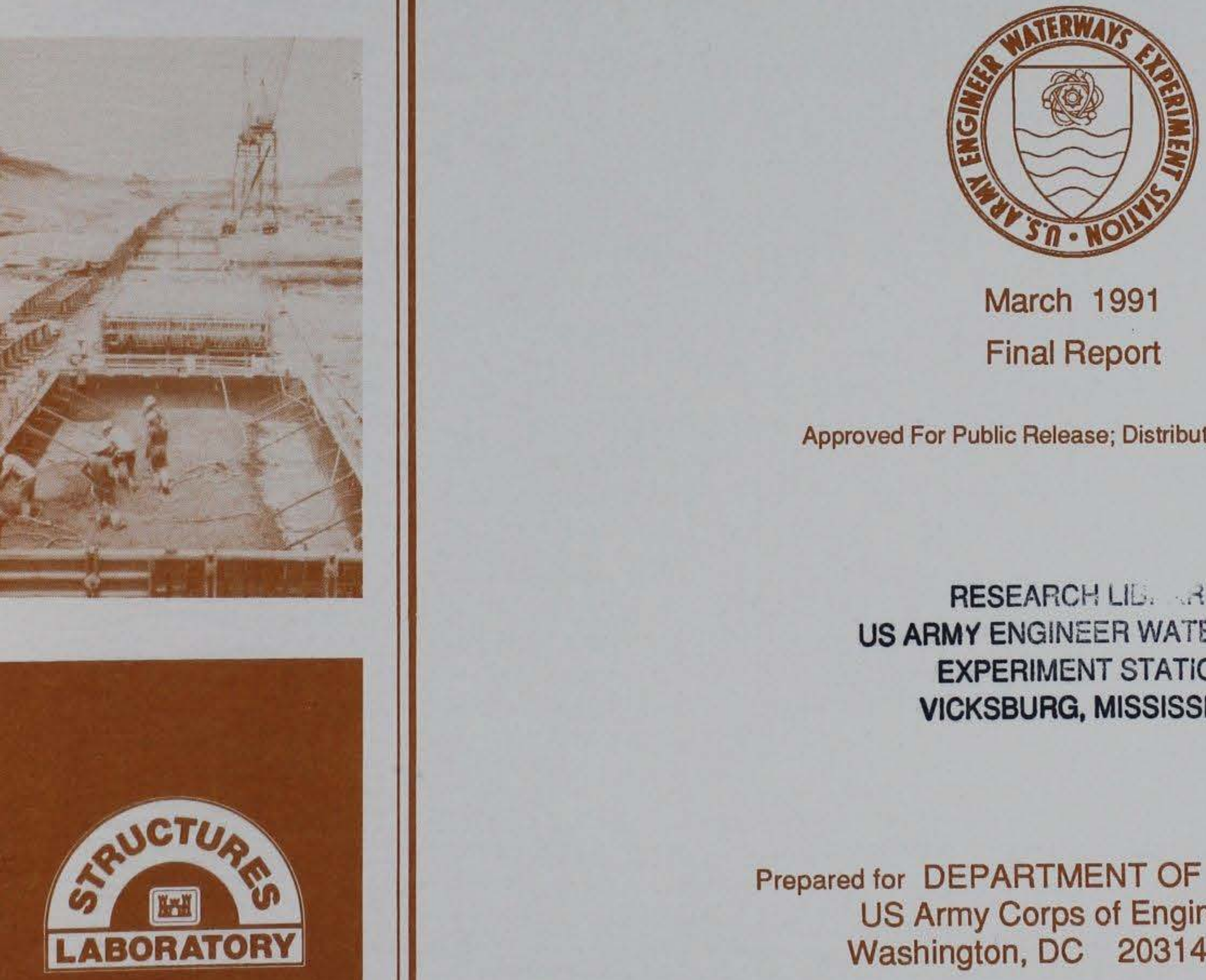

March 1991

Final Report

Approved For Public Release; Distribution Unlimited

RESEARCH LIL: RY

US ARMY ENGINEER WATERWAYS

EXPERIMENT STATION

VICKSBURG, MISSISSIPPI

Prepared for DEPARTMENT OF THE ARMY

US Army Corps of Engineers

Washington, DC 20314-1000 
Public reporting burden for this collection of information is estimated to average 1 hour per response, including the time for reviewing instructions, searching existing data sources. gathering and maintaining the data needed, and completing and reviewing the collection of information. Send comments regarding this burden estimate or any other aspect of this Davis Highway, Suite 1204 , Arlington. VA 22202.4302 , and this burden. to Washington Headquarters Services, Directorate for information Operations and Reports. 1215 Jefferson D.

\begin{tabular}{|l|l|l|}
\hline 1. AGENCY USE ONLY (Leave blank) & 2. REPORT DATE & 3. REPORT TYPE AND DATES COVERED
\end{tabular}

4. TITLE AND SUBTITLE March 1991 Final Repart

Evaluation of a Software Program for Storing, Computing

and Reporting Concrete Test Results

6. AUTHOR(S)

Roy L. Campbe11, Sr.

7. PERFORMING ORGANIZATION NAME(S) AND ADDRESS(ES)

USAE Waterways Experiment Station

Structures Laboratory

3909 Halls Ferry Road

Vicksburg, MS 39180-6199

9. SPONSORING/MONITORING AGENCY NAME(S) AND ADDRESS(ES)

5. FUNDING NUMBERS

US Army Corps of Engineers
Washington, DC 20314-1000

\section{SUPPLEMENTARY NOTES}

Available from National Technical Information Service, 5285 Port Royal Road, Springfield, VA 22161

12a. DISTRIBUTION/AVAILABILITY STATEMENT

12b. DISTRIBUTION CODE

Approved for public release; distribution unlimited

\section{ABSTRACT (Maximum 200 words)}

The Computer Applications in Geotechnical Engineering (CAGE) Materials Quality Assurance (QA) Task Group identified the need for the computerization of concrete quality assurance and quality control (QC) data at Corps construction projects. One area of program development was the processing of concrete test data in which a commercial software program called SeeSTAT was selected for evaluation.

The SeeSTAT software is a menu-driven program that utilizes pop-up menus to minimize user entries. Computations made by the program include statistical analysis needed to evaluate test results in accordance with ACI 214-77, "Recommended Practice for Evaluation of Strength Test Results of Concrete." Frequency distribution and regression analyses are also available options for analyzing test results. Results can be output in tabular and graphic forms to a printer.

(Continued)

\section{SUBJECT TERMS \\ Concrete test results \\ Frequency distribution \\ Quality assurance

17. SECURITY CLASSIFICATION
OF REPORT
UNCLASSIFIED

NSN 7540-01-280-5500
8. PERFORMING ORGANIZATION

Miscellaneous Paper SL-91-2

SPONSORING / MONITORING AGENCY REPORT NUMBER

\section{Software}

Statistical analysis

Time-1ine analysis

\section{NUMER OF PAGES \\ 15. NUMBER OF PAGES
27}

16. PRICE CODE

20. LIMITATION OF ABSTRACT

\begin{tabular}{l|l}
\hline SECURITY CLASSIFICATION & $\begin{array}{l}19 . \\
\text { OF THIS PAGE } \\
\text { OF ABSTRACT }\end{array}$
\end{tabular}

OF ABSTRACT

UNCLASSIFIED

Standard Form 298 (Rev. 2-89)

Prescribed by ANSI Std. 239-18 298-102 


\section{3. (Concluded).}

The tabular output can be stored to a disk file in ASCII (text) format that allows for word processing and electronic mailing.

Program limitations are noted in the report with possible remedies presented for many. Examples of tabular and graphic outputs presented in the report were imported from SeeSTAT: the tables directly from tabular output and graphs indirectly through use of a screen-scan routine.

It was concluded that the SeeSTAT program met the Corps of Engineers' software needs for storing, computing, and reporting concrete test data generated during a construction project. It was recommended that the SeeSTAT software be considered for use Corps-wide and, at projects where software is employed, disks containing concrete test results accompany the distribution of the concrete report. 


\section{PREFACE}

The work described in this report was authorized by Headquarters, US Army Corps of Engineers (HQUSACE), as part of the Computer Applications in Geotechnical Engineering (CAGE) Project sponsored by HQUSACE.

Mr. Ear1 V. Edris, US Army Engineer Waterways Experiment Station (WES), Geotechnical Laboratory, Soil and Rock Mechanics Division, was principal investigator of the CAGE Project. Mr. M. K. Lee, HQUSACE (CECW-EG), was Technical Monitor for this work. Mr. Thomas L. Hugenberg, US Army Engineer Division, Ohio River (CEORD), was the Task Group Chairman of the CAGE Materials Quality Assurance Task Group for the publishing of this report.

The work was performed as a part of the Materials Quality Assurance Task Group. The task group members, through their experience and expertise, provided valuable input needed for evaluation of software applicability. Their contributions are acknowledged and greatly appreciated by the author of this report. Members of the committee are:

Mr. Fred Anderson, formerly with HQUSACE (CECW-EG)

Mr. Rich Carr, HQUSACE (CEMP-CE)

Mr. Byron Foster, US Army Engineer Division, South Atlantic (CESAD)

Mr. James K. Hinds, US Army Engineer Division Laboratory, North Pacific (CENPD)

Mr. Thomas L. Hugenberg, CEORD

Mr. M. K. Lee, HQUSACE (CECW-EG)

Mr. Charles Stevenson, US Army Engineer District, Pittsburgh (CEORP)

Mr. Stephen Tatro, US Army Engineer District, Walla Walla (CENPW)

Mr. Roy L. Campbell, Sr., (CEWES-SC)

Mr. Gordon Loudin, US Army Engineer District, Huntington, and Mr. George Sledge, US Army Engineer District, Mobile, conducted the field evaluations of the software at new Gallipolis Locks and new Oliver Locks, respectively. Their contributions are acknowledged and also greatly appreciated.

This report was prepared at WES by Mr. Roy L. Campbe11, Sr., Structures Laboratory (SL), Concrete Technology Division (CTD), under the general 
supervision of Messrs. Bryant Mather and James Ballard, Chief and Assistant Chief, SL, respectively, and Mr. Kenneth Saucier, Chief, CTD.

Commander and Director of WES was COL Larry B. Fulton, EN. Technical Director was Dr. Robert W. Whalin. 
CONTENTS

Page

PREFACE. . . . . . . . . . . . . . . . . . . . . . . . . . . . . . . . 1

CONVERSION FACTORS, NON-SI TO SI (METRIC) UNITS OF MEASUREMENT . . . . . . 4

PART I: INTRODUCTION . . . . . . . . . . . . . . . . . . . 5

Background . . . . . . . . . . . . . . . . . . . . . . . . . . . . . 5

Purpose . . . . . . . . . . . . . . . . . . . . . 5

PART II: PROGRAM EVALUATION . . . . . . . . . . . . . . . . . . . . . . 7

Group Evaluation . . . . . . . . . . . . . . . . . . . . . . . . . . . . . 7

Field Evaluation . . . . . . . . . . . . . . . . . . . . . 7

PART III: PROGRAM REQUIREMENTS . . . . . . . . . . . . . . . . . . . . . 8

Hardware . . . . . . . . . . . . . . . . . . . . . . . . . . . . . . 8

Software . . . . . . . . . . . . . . . . . . . . . . 8

PART IV: PROGRAM FEATURES . . . . . . . . . . . . . . . . . . . . . . . 9

General . . . . . . . . . . . . . . . . . . . . . . . . . . . . . . . 9

Data Entry/Edit. . . . . . . . . . . . . . . . . . . . . . . . . . 9

Data Retrieval . . . . . . . . . . . . . . . . . . . . . . . . 10

Analysis Options . . . . . . . . . . . . . . . . . . . . . . . . . . . . . 10

Output Options . . . . . . . . . . . . . . . . . . . . . . . . . . . . . . 13

PART V: PROGRAM LIMITATIONS/DEFICIENCIES . . . . . . . . . . . . . . . . 18

PART VI: CONCLUSIONS AND RECOMMENDATIONS . . . . . . . . . . . . . . . . 21

REFERENCES . . . . . . . . . . . . . . . . . . . . . . . . . . . 22 
CONVERSION FACTORS, NON-SI TO SI (METRIC) UNITS OF MEASUREMENTS

Non-SI units of measurements used in this report can be converted to SI (metric) units as follows:

Multiply

inches

Fahrenheit degrees

pounds (force) per square inch pounds (mass) per cubic foot
By

25.4

$5 / 9$

0.006894757

16.01846
To Obtain

millimetres

Celsius degrees or kelvins* megapascals

kilograms per cubic metre

* To obtain Celsius (C) temperature readings from Fahrenheit (F) readings, use the following formula: $C=(5 / 9)(F-32)$. To obtain Kelvin $(K)$ readings, use: $\quad K=(5 / 9)(F-32)+273.15$. 


\section{EVALUATION OF A SOFTWARE PROGRAM FOR STORING, COMPUTING, \\ AND REPORTING OF CONCRETE TEST RESULTS}

\section{PART I: INTRODUCTION}

\section{Background}

1. The Computer Applications in Geotechnical Engineering (CAGE) Materials Quality Assurance (QA) Task Group identified the need for the computerization of concrete quality assurance and quality control (QC) data at Corps construction projects. Through computerization, tracking of concrete quality and reporting of results would be easier. Also, retrieval of data for settling contractors' claims and storing of data for inclusion in the concrete report at the end of the project would be facilitated.

2. One area of program development was the processing of concrete test data. An alternative to writing a new code was to adapt for use the personal computer (PC) version of the Corps Computer Library System Program, X0064, called "CONEVAL" (Campbe11, 1982). However, this version was like that of the mainframe's in that it had a rigid input format and very limited capabilities as far as data retrieval and output.

3. Another alternative was to substitute a commercial software program. Such programs generally have a wide range of hardware compatibility and are likely to be maintained to include changes in technology and current practices. Three commercial software programs, CPR by Von Gunten Engineering Software, SeeSTAT by Shilstone Software Company, and TesTrak by Forney, were considered. Based on a review of vendor brochures and demonstration disks, the SeeSTAT program best met the Corps' needs as far as data input, retrieval, analysis, and output features; analysis and output flexibility; and ease of use.

\section{Purpose}

4. The purpose of this investigation was to evaluate the applicability of the SeeSTAT program for meeting the Corps of Engineers' software needs for 
storing, computing, and reporting of concrete test results generated at a construction project. 


\section{PART II: PROGRAM EVALUATION}

\section{Group Evaluation}

5. The SeeSTAT program was evaluated by the CAGE Materials QA Task Group through a demonstration by the Shilstone Software Company in which the vendor presented program uses and features in relation to the Corps' needs. The group concluded that the program appeared to meet the Corps' software needs for processing concrete strength test results and to be unique in its capability to provide a useful data base format for all projects involving the placement of concrete.

\section{Field Evaluation}

6. The SeeSTAT program was employed for an approximate 6-mo period at two concrete construction projects, the new Gallipolis Locks in the Huntington District and the new Oliver Locks in the Mobile District. Field personnel were asked to evaluate the program for applicability and ease of use. Both projects reported the overall acceptance of the program for (a) being easy to use, (b) providing statistical output needed for the analyzing and reporting of concrete test results, and (c) establishing a data base of test results on unhardened and hardened concrete. 


\section{PART III: PROGRAM REQUIREMENTS}

\section{Hardware}

7. SeeSTAT requires IBM PC, AT, XT, PS/2 or compatible computer with a minimum of 512-k random access memory (RAM). Computer should contain a hard disk drive having a 20-megabyte (MB) storage capacity or greater and a Color Graphics Adapter (CGA), Extended Graphics Adapter (EGA), or Video Graphics Adapter (VGA) card. Printer must be parallel and able to emulate an "Epson" graphics format. Compatible printers include most Epson printers, the IBM Proprinter, and many other brand printers.

\section{Software}

8. SeeSTAT requires the disk operating system to be MS-DOS or PC-DOS, version 2.1 or later. 


\section{PART IV: PROGRAM FEATURES}

\section{General}

9. SeeSTAT is a menu-driven software program that provides computerized storing, computing, and reporting of project concrete test results and increased capabilities for analyzing concrete strength results. The number of keystrokes needed to complete a task is minimized by use of pop-up menus that use arrow keys to locate an option or field and the enter or function key to select. Computations include statistical output needed to evaluate test results in accordance with ACI 214-77, "Recommended Practice for Evaluation of Strength Test Results of Concrete." Time-line graphs can be generated to facilitate the identification of changes in concrete quality and testing. Frequency distributions can be produced to identify how well the test results fit a normal frequency distribution curve. Regression analysis can be performed to determine the correlation between sets of independent and dependent results and to make predictions based on correlation. Tabular reports can be output to disk file in ASCII (text) format that allows for word processing and electronic mailing.

\section{Data Entry/Edit}

10. The data entry/edit option from the main menu is selected to enter or edit data records. Data entry fields include: mixture identification, design strength, sample identification, date sampled, mixture modification number, batch weights for cement and fly ash, three user definable fields (defaults: time batched, time sampled, ticket number), slump, air content, concrete and air temperatures, concrete unit weight, batch size, weight of water added on job, five single-character user codes (flags that identify samples for retrieval as a block), and cylinder data. Cylinder data fields include: cylinder identifier, age, compressive strength, and a user-definable field (default: flexural strength). 


\section{Data Retrieva1}

11. Data are retrievable by mixture identification and certain fields that allow search conditions to be imposed. These fields include: sample identification and date, modification number, cementitious material contents, slump, air content, concrete and air temperatures, concrete unit weight, cement efficiency, weight of water added on job, user codes, compressive strength, flexural strength, difference between within-test compressive strengths, and ratio of compressive strengths for 7- and 28-day ages. Search conditions include: less than a certain value, equal to a certain value, greater than a certain value, between a set of lower and upper values, not equal to value or range of values, and others.

12. The search condition is a powerful tool that allows the user to target a specific group of samples for analysis and reporting. Multiple conditions can be imposed; for example, retrieve only samples made between 1 January and 31 January where 7- and 90-day compressive strengths are greater than zero. For the field evaluations, the five user codes were used to identify the location from which a sample was taken. The first code contained a character to identify the structural element, such as an " $R$ " for river wall. The next two codes identified the monolith number, and the last two the lift number. Using this coding system, data for all samples of a mixture placed in a specified element, monolith(s), or lift(s) can be retrieved as a group for analysis and reporting.

\section{Analysis Options}

13. The analysis procedure menu offers four choices: tabular results, time-line analysis, frequency distribution, and regression analysis.

\section{Tabular results}

14. The tabular option is used to generate tables of data to include statistical values for evaluation by ACI 214. The data for each sample meeting search condition(s) are displayed in user-ordered columns. Column selection may be for any one of the data entry fields, fields with imposed search conditions, casting sequence, or statistical data. Statistical data include 
cumulative and moving averages, cumulative and moving standard deviations, and moving averages for the within-test coefficient of variation. User-selected column tabulations are displayed at bottom of table and may include count, average, standard deviation, range, and coefficient of variation. An ACI 214 summary table for 28-day strength test results is also generated as a part of tabular output. Examples of tabular output depicting user-selected columns for data input and statistical results are presented in Tables 1 and 2 ,* respectively.

Table 1. User-Selected Columns Depicting Data Input

\begin{tabular}{|c|c|c|c|c|c|c|c|c|c|c|c|}
\hline Sample & Mod: & $\begin{array}{l}\text { Date } \\
\text { sampled }\end{array}$ & $\begin{array}{l}\text { User } \\
\text { codes }\end{array}$ & $\begin{array}{c}\text { Air } \\
\text { deg } \\
\text { deg }\end{array}$ & $\begin{array}{c}\text { con } \\
\text { Tmp } \\
d e g\end{array}$ & conitrent & slump & $\begin{array}{c}\text { Unit } \\
\text { weight } \\
\text { pef }\end{array}$ & $\begin{array}{c}7 \text { pay } \\
\text { comp } \\
\text { psi }\end{array}$ & $\begin{array}{c}28 \text { Day } \\
\text { Comp } \\
\text { psi }\end{array}$ & $\begin{array}{c}\text { Indiv } \\
\text { cy| } \\
\text { 90 Day } \\
\text { coinp } \\
\text { psi }\end{array}$ \\
\hline 001 & 1 & $3 / 10 / 89$ & $R 0700$ & - & 64 & 6.4 & 3.00 & $=$ & $\begin{array}{l}=7=7=7 \\
1468\end{array}$ & 2635 & 4067 \\
\hline 002 & 1 & $3 / 15 / 89$ & $L 11000$ & - & 73 & 5.7 & 3.25 & - & 1485 & 2653 & \\
\hline 003 & 1 & $3 / 17 / 89$ & $\begin{array}{llllll}R & 0 & 7 & 0 & 1\end{array}$ & - & 64 & 5.0 & 4.25 & - & 1397 & 2617 & $\begin{array}{l}4244 \\
4156\end{array}$ \\
\hline 006 & 1 & $3 / 28 / 89$ & $R O 900$ & - & 73 & 6.0 & 3.25 & 147.7 & 1468 & 2812 & $\begin{array}{l}4350 \\
4386\end{array}$ \\
\hline 008 & 1 & $3 / 31 / 89$ & $R O 500$ & - & 56 & 7.5 & 4.25 & 143.3 & 1149 & 2334 & $\begin{array}{l}3724 \\
3724 \\
3608\end{array}$ \\
\hline
\end{tabular}

Table 2. User-Selected Columns Depicting Statistical Output

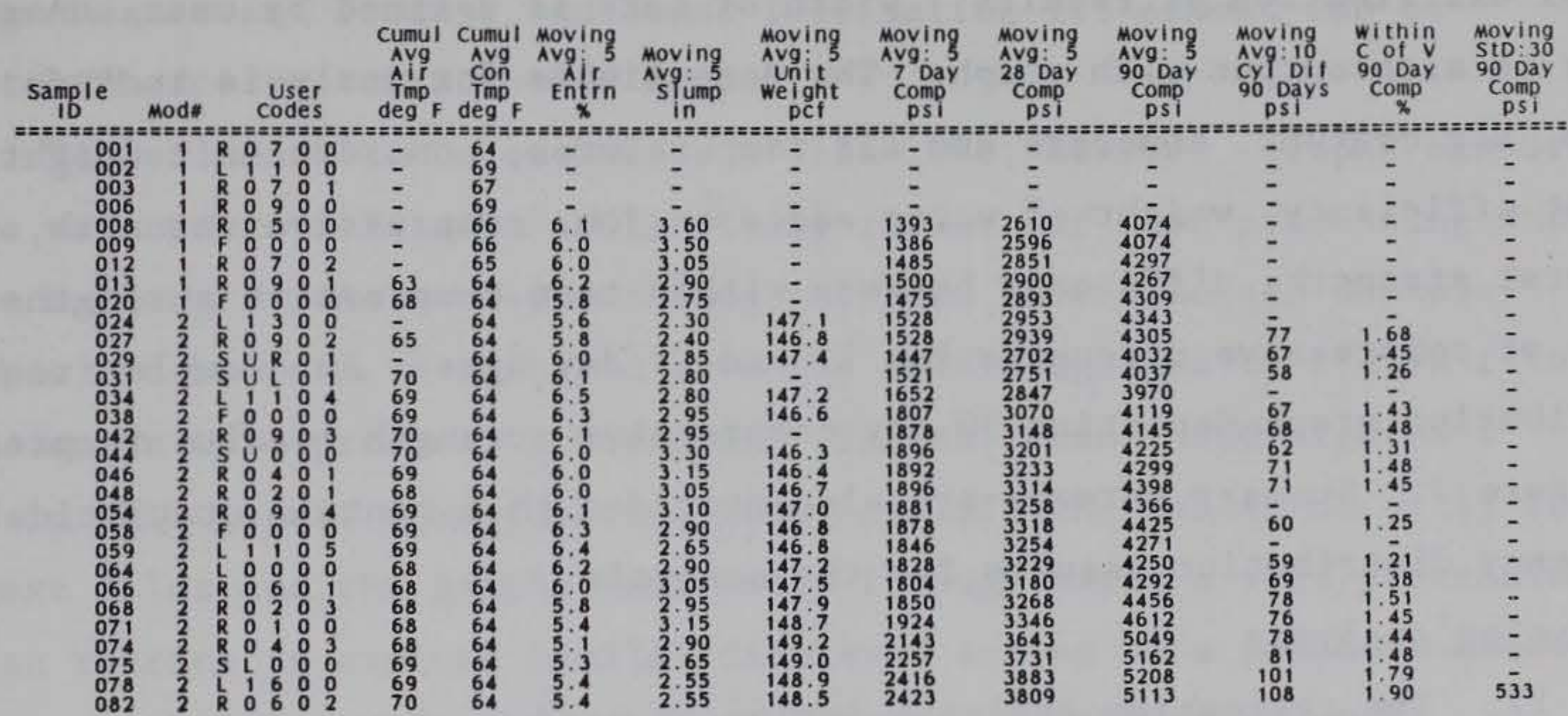

* A table of factors for converting non-SI units of measurement to SI (metric) units is presented on page 4. 
Time-line analysis

15. The time-line analysis option is used to track changes in test results with time (casting sequence). Data fields include: slump; air content; concrete and air temperatures; concrete unit weight; cement efficiency; weight of water added on job; compressive strength; flexural strength; ratio of compressive strengths for 7-and 28-day ages; cumulative averages and standard deviations; and for two or more cylinder results, individual results; within-test averages, cumulative averages, and moving averages; ranges; and moving averages for range. Reference values (those constant with time, such as specified and required average strengths) can also be included. Time-line graphs that are likely to be reported are as follows: air content (Figure 1); slump (Figure 2); 30-test, moving standard deviation (Figure 3); 30-test, moving averages for the within-test coefficient of variation (Figure 4); 5-test, moving averages (Figure 5); and 10-test, moving average for range (Figure 6). A summary screen is also provided that contains statistical results for the analysis.

\section{Frequency distribution}

16. The frequency distribution option is used to display how often a test result occurs. The frequency distribution graph consists of a bell curve representing a normal frequency distribution and a bar chart representing the actual distribution of results. Width of bars is defined by user. A summary table is also output with graph. The data fields for analysis include: slump, air content, concrete and air temperatures, concrete unit weight, cement efficiency, weight of water added on job, compressive strength, flexural strength, difference between within-test compressive strengths, and ratio of compressive strengths for 7 - and 28-day ages. An example frequency distribution graph depicting 90-day compressive strength results is presented in Figure 7. Summary screens are also provided that contain statistical and frequency distribution results for the analysis.

Regression analysis

17. The regression analysis option is used to determine the relationship between user-specified data fields. The correlation between fields is defined using both linear and polynomial analyses in which a dependent and one or more independent fields are used. Data fields for analysis include: casting sequence, slump, air content, concrete and air 
temperatures, concrete unit weight, cement efficiency, weight of water added on job, compressive strength, flexural strength, difference between withintest compressive strengths, and ratio of compressive strengths for 7 - and 28 day ages.

18. The resulting correlation equations are used to compute predicted values for the dependent variable from user-entered data for the independent variable(s). The most practical application for Corps needs is the linear regression analysis where test results for early age compressive strengths can be used to predict later age compressive strengths. An example graph depicting regression analysis results is presented in Figure 8 . In the example, 7-day compressive strength was selected as the independent variable and 90-day compressive strength as the dependent. Summary screens are also provided that contain correlation and prediction results.

\section{Output Options}

19. Tables and graphs displayed on the computer screen can be output to a printer. The printer setup option can be used to send code for formatting printer. This option can be used to generate the compressed printing of tables that are wider than 80 characters, such as Tables 1 and 2 . Report title, page header and footer, and owner information letterhead can be employed to enhance presentation of output.

20. Tables can also be output to a disk file; however, graphs cannot. Tables are written to a file in ASCII (text) format for word processing and electronic mailing. Some word-processing packages have a screen-capture program that can be used to scan and save the SeeSTAT graphs to a disk file for inclusion in word-processing document. Tables 1 and 2 and Figures 1 through 8 in this report were imported from SeeSTAT, the tables directly from SeeSTAT text files and the graphs indirectly through using a word-processing screen scan routine to capture SeeSTAT displayed screen to a graphics file. File content was then imported directly into word-processing document. 


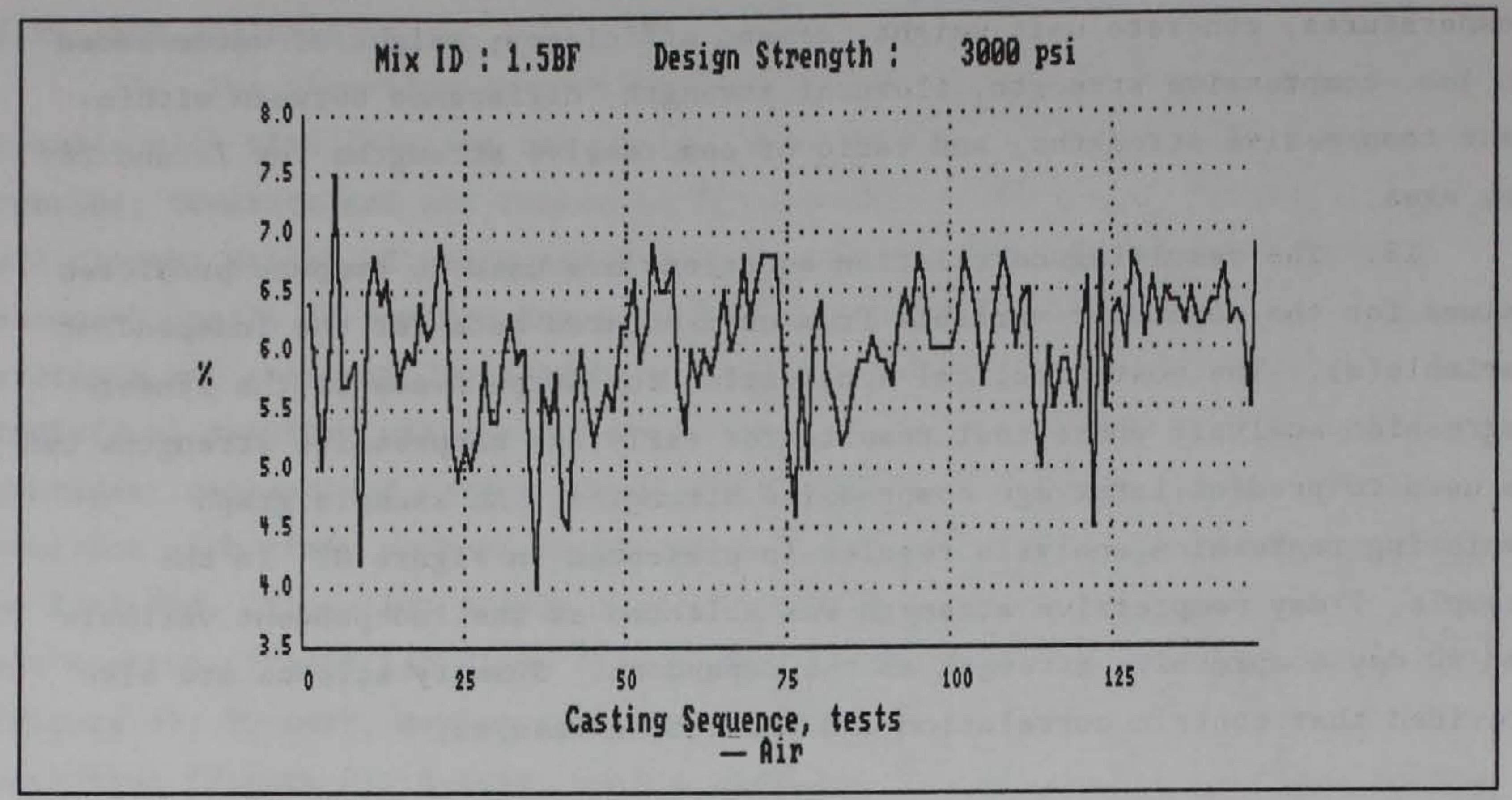

Figure 1. Time-line graph for air content

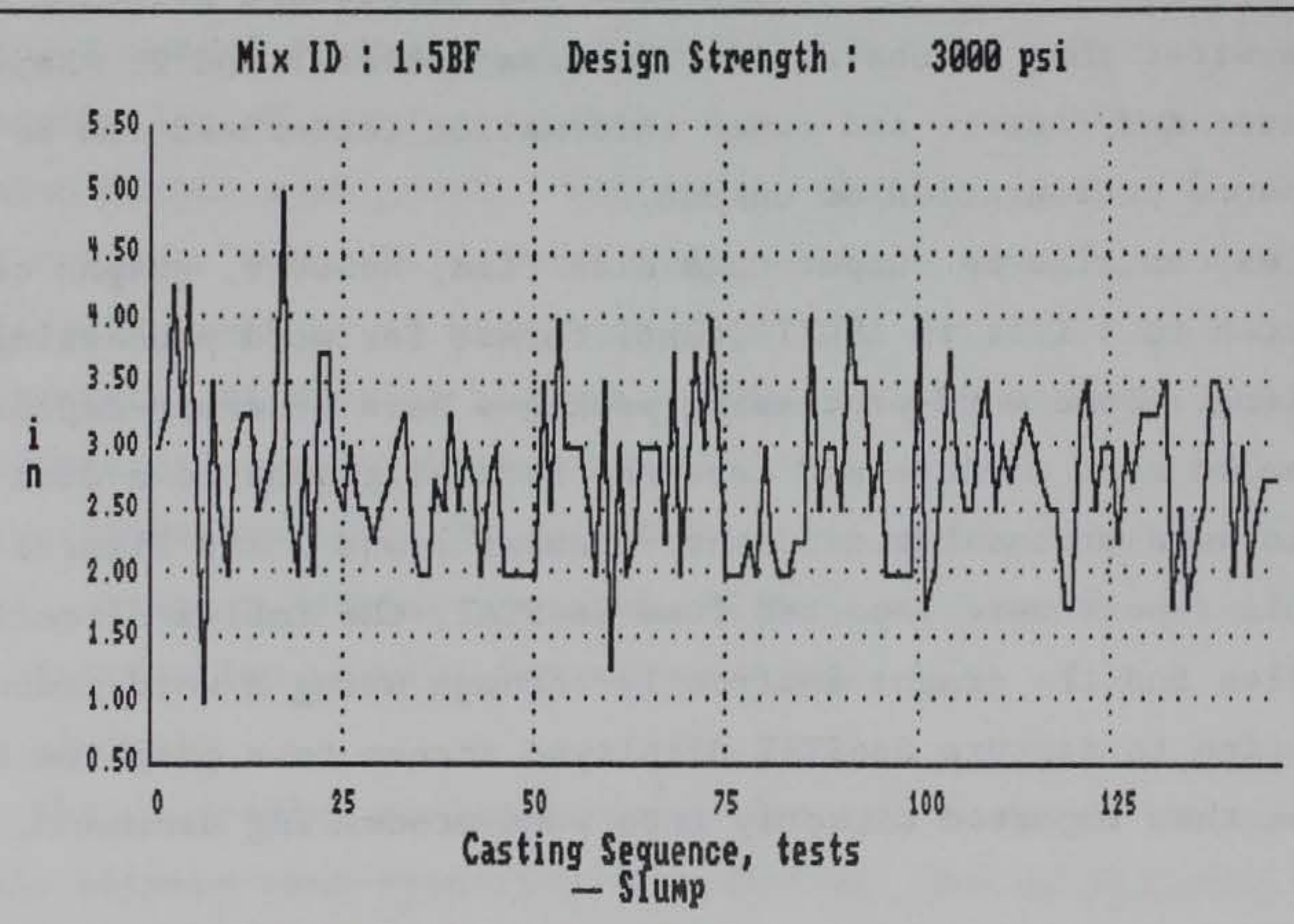

Figure 2. Time-1ine graph for slump 


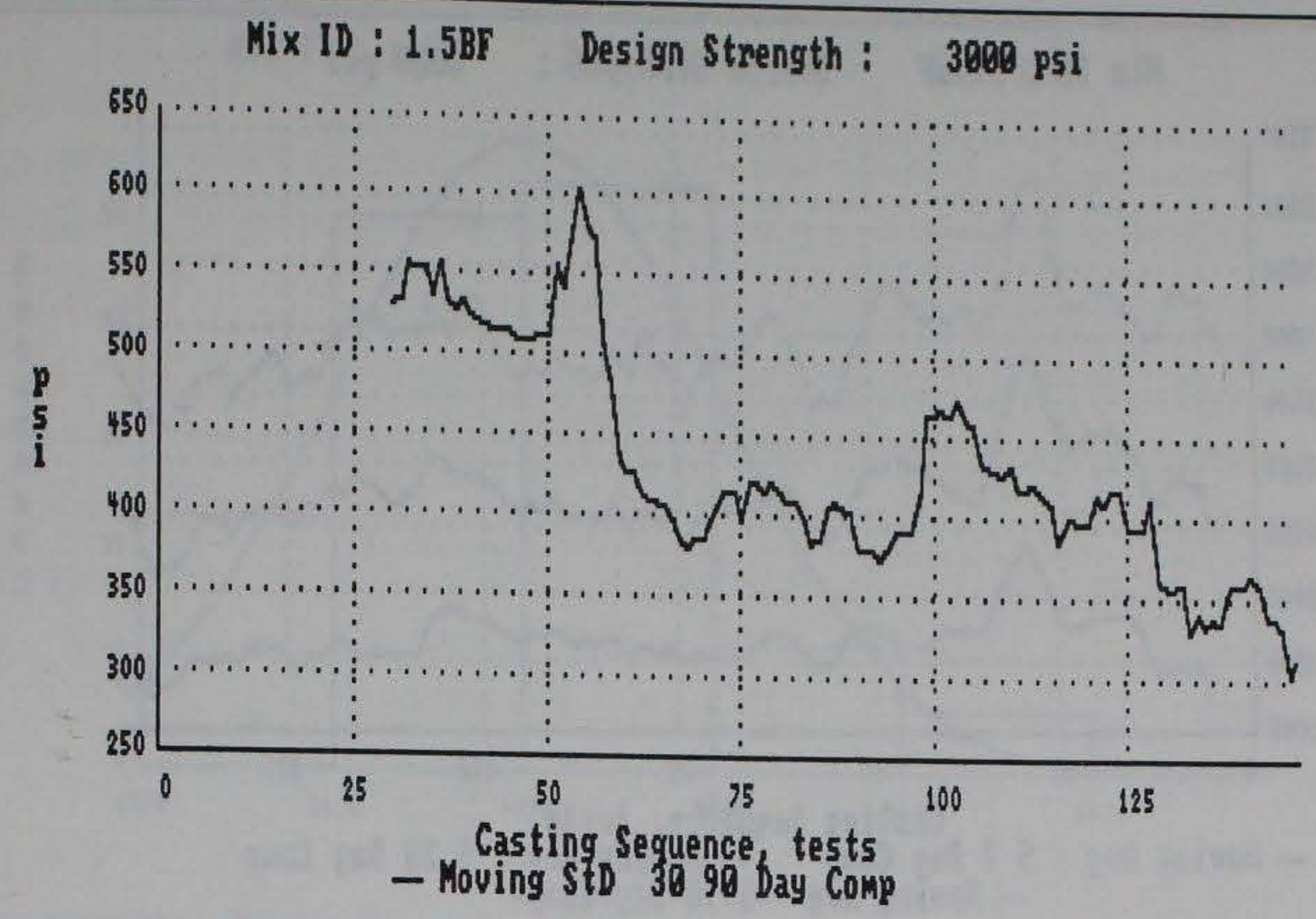

Figure 3. Time-line graph for moving standard deviation

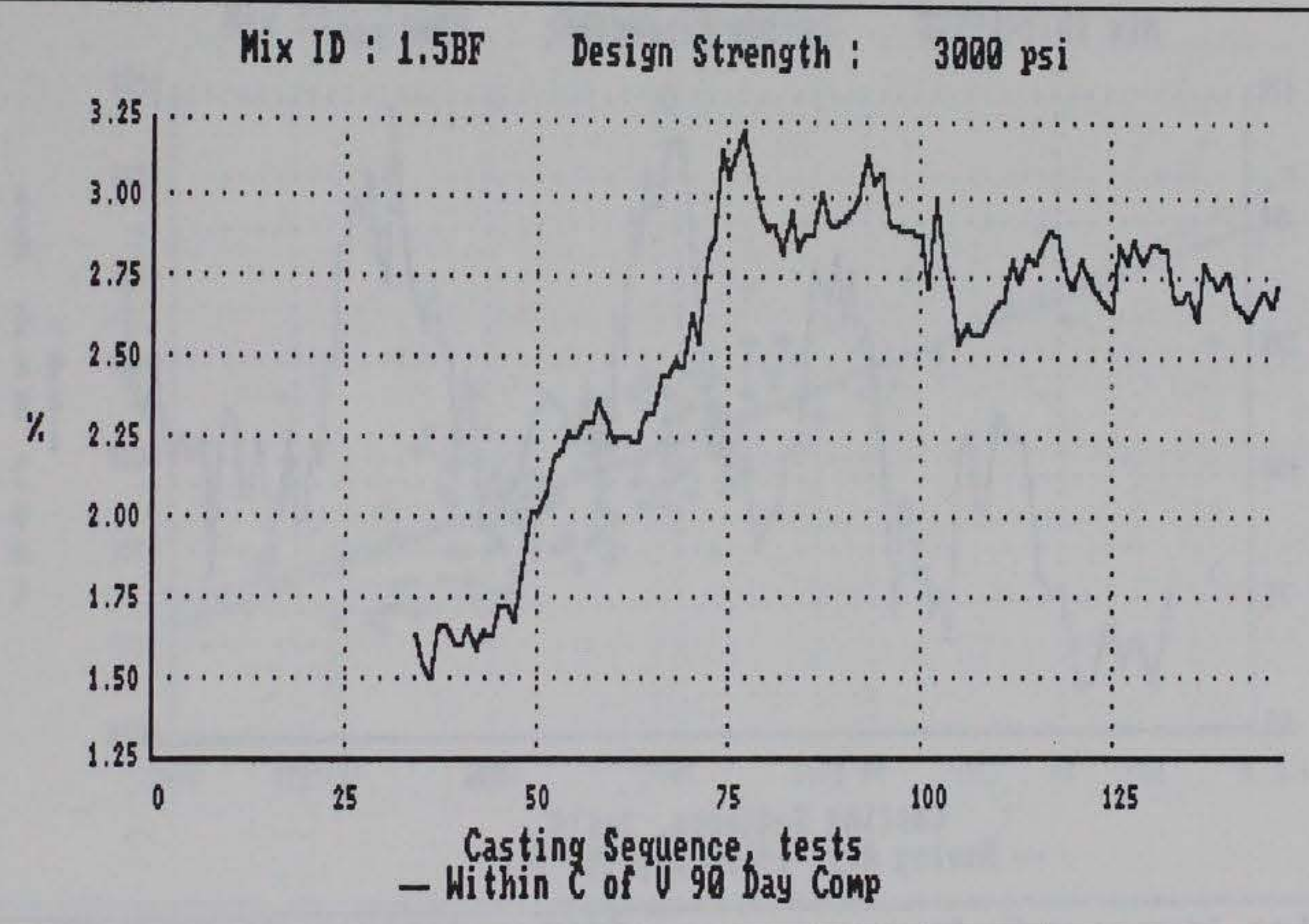

Figure 4. Time-line graph for moving within-test coefficient of variation 


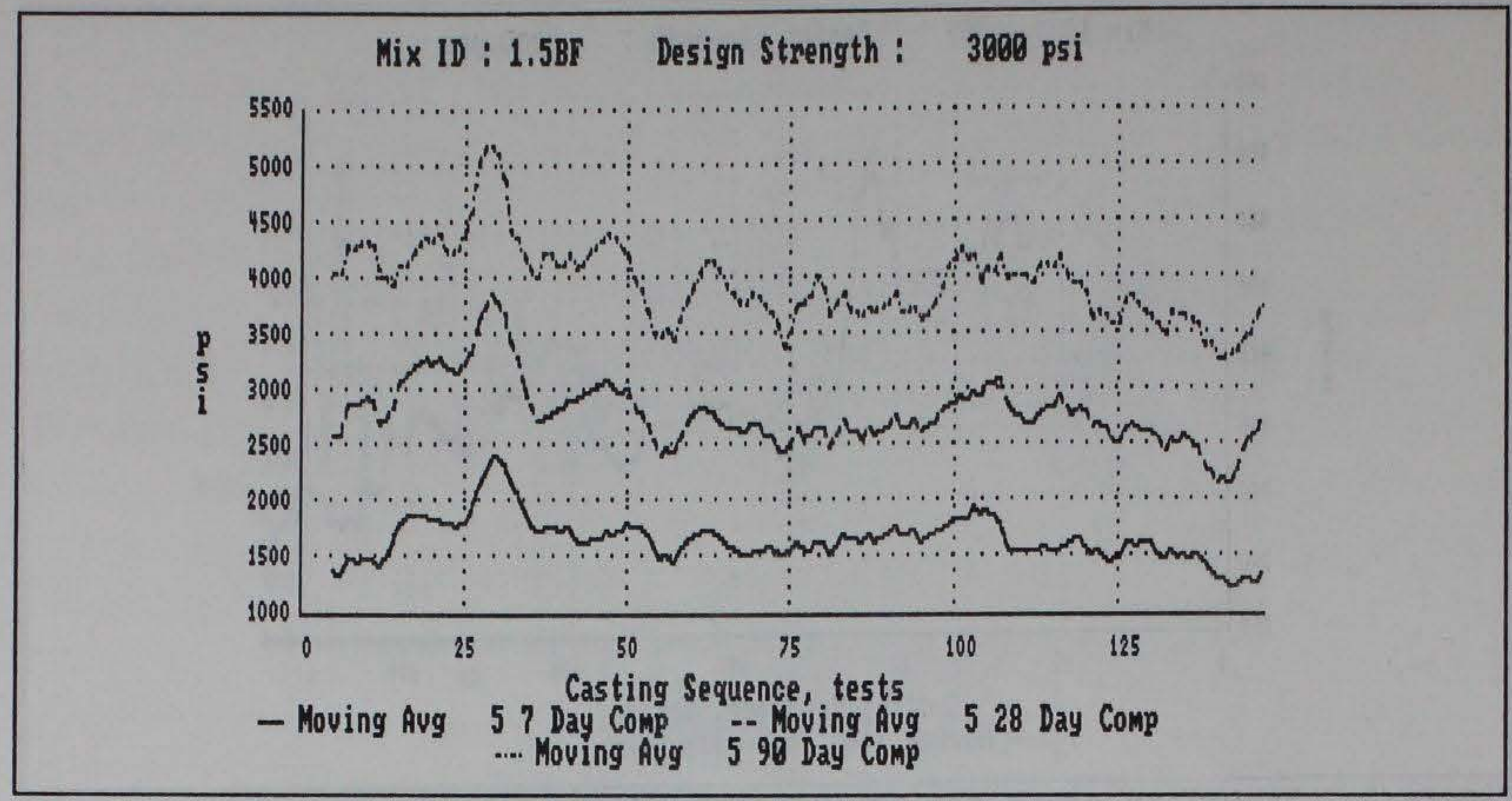

Figure 5. Time-line graph for compressive strengths

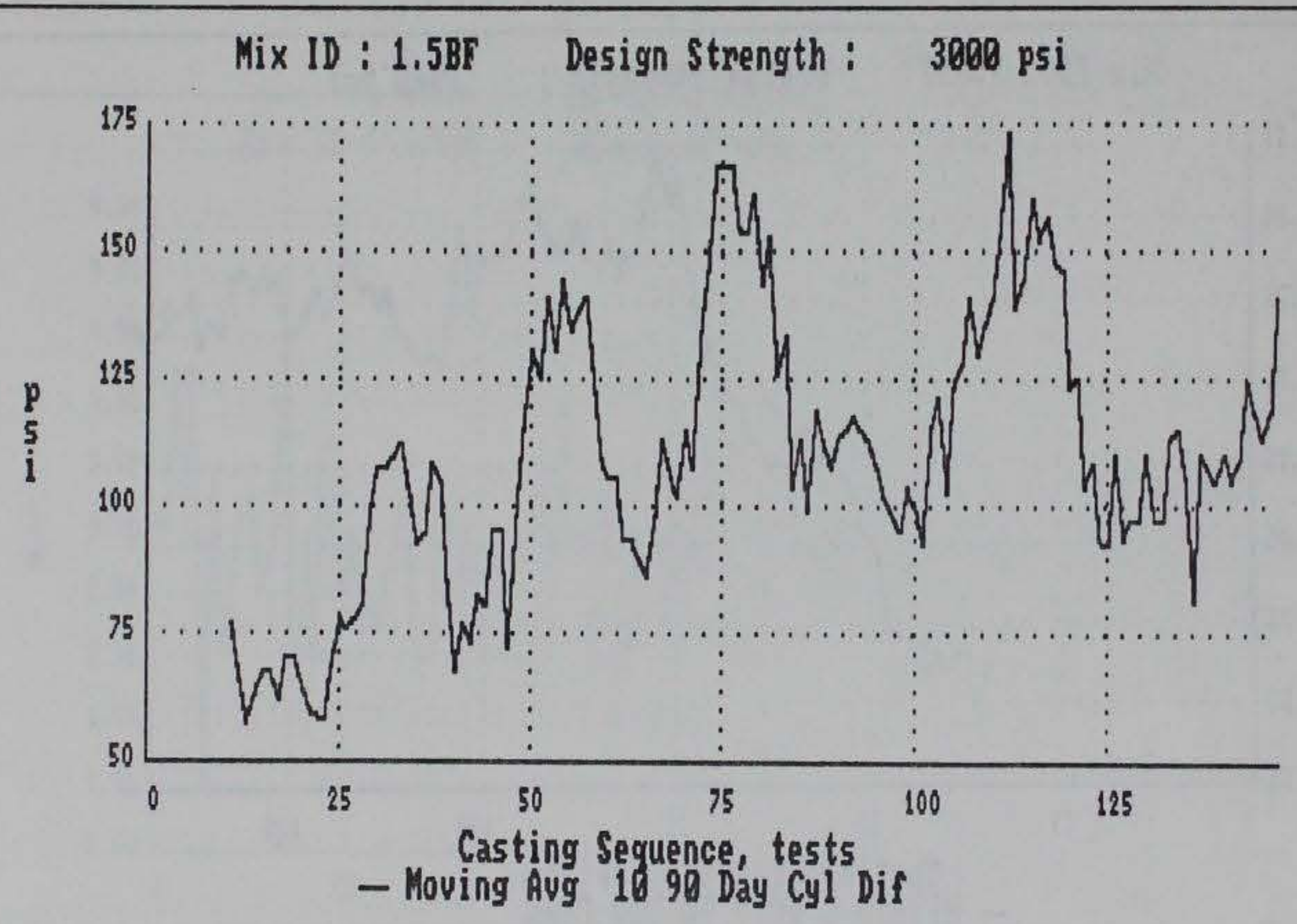

Figure 6. Time-line graph for moving average of range 


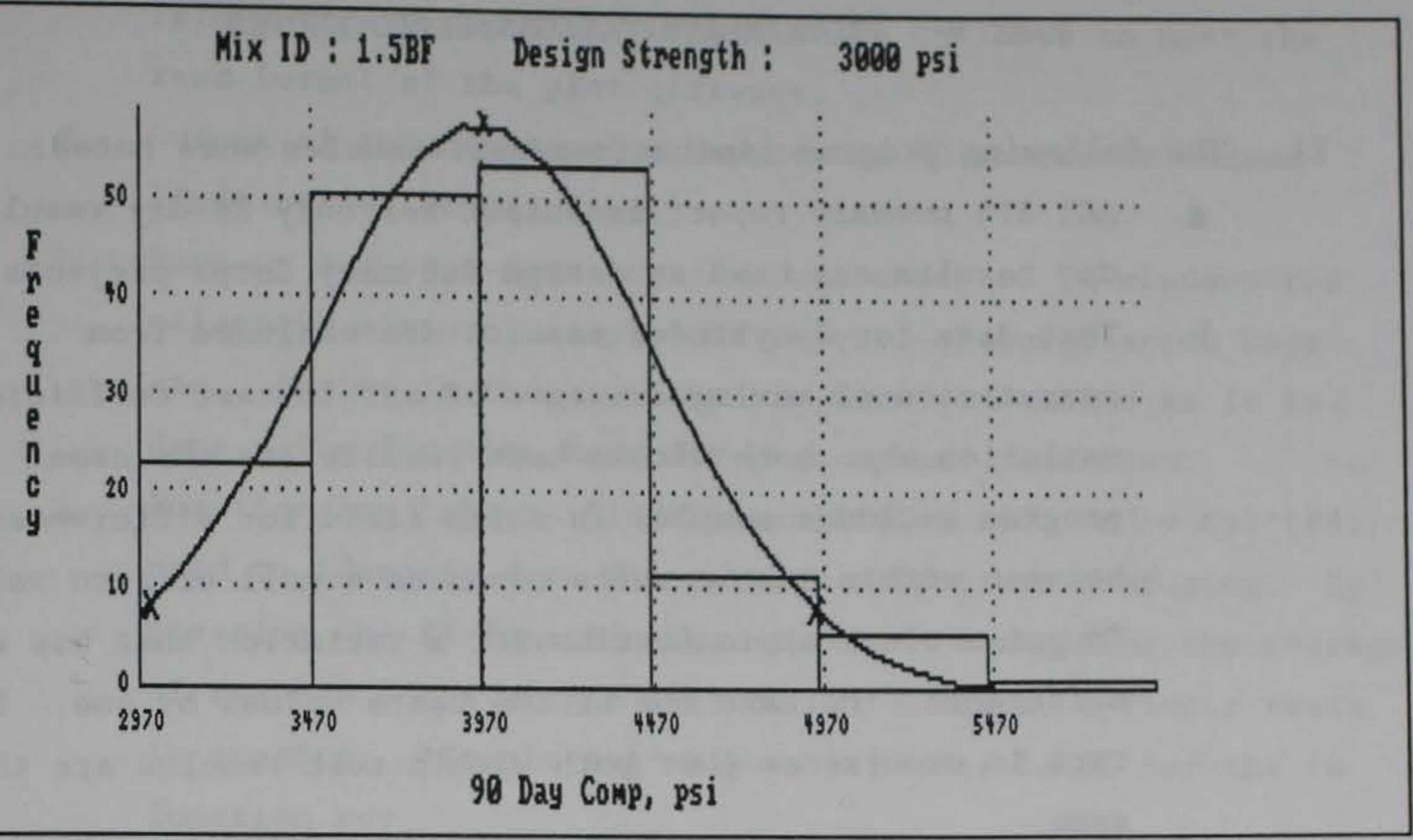

Figure 7. Frequency distribution graph

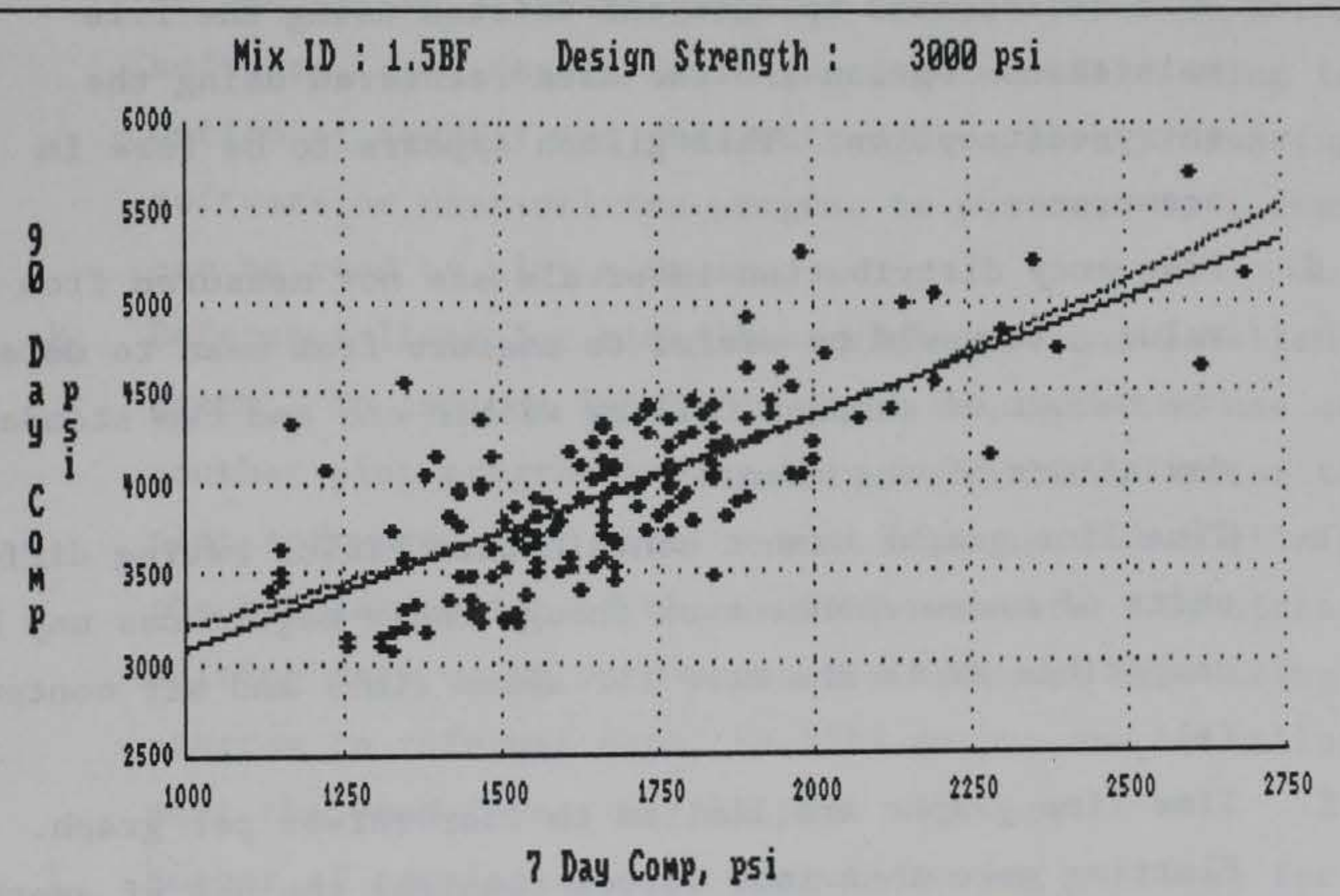

Figure 8. Regression analysis graph 
21. The following program limitations/deficiencies were noted:

a. ACI 214 summary report is output for only 28 -day results ( 90 day results are used as design for many Corps projects).

b. Test data for 2-cylinder results are excluded from computation of moving averages of within-test coefficient of variation when both within-test results are the same. The program excludes samples in which field for differences between within-test results contains a null or zero value. To get a close approximation for a variation that has a zero difference, increase one of the tests values by one. It is rare in occurrence that both within-test results are the same.

c. A certain unidentified combination of keystrokes prior to or during entry of sample identification will cause the data to be left justified. To right justify the data, the record must be accessed by date and deleted using the file maintenance option and the data reentered using the entry/edit option. This glitch appears to be rare in occurrence.

d. Frequency distribution intervals are not measured from mean value. It would be useful to measure from mean to determine the number of samples falling within one and two standard deviations of the mean.

e. Time-line graphs cannot contain data fields having different units of measurements even though their magnitudes may be compatible as is the case for slump (in.) and air content (8).

f. Time-line graphs are limited to four curves per graph. Plotting more than four curves requires the use of another plot program having this capability. Prior to using plot software, test results must be output to a file using the tabular option of the SeeSTAT software. By either editing data using word- processor software or writing a program to 
reformat data, SeeSTAT output can be tailored to meet the read format of the plot software.

g. Output of tabular results beyond the 80 -character screen limit cannot be displayed.

h. Page-up and page-down keys are not accepted in windows for selecting mixture, sample, or report, although arrow keys are. Paging in these windows is more cumbersome as it is done using function keys for page-up and page-down.

i. Function key labels, "Indiv Result"(f4) and "Indiv Cyl"(f8), used to identify data for tabular output are confusing. By pressing the $\mathrm{f} 4$ function key, a column containing the average of results for a single cylinder or multiple cylinder tests is created. "Sample Avg" may be a better label for the f4 function key.

i. Graphs cannot be saved to disk file by program. Graphs can be saved to a file using commercial screen scan software or using plot software that can replot results and store image in one of the standard graphics forms. Prior to using plot software, test results must be output to file using tabular option of SeeSTAT and then edited by a word-processing software or user-written program to put data in a form that can be read by plot software.

k. Reference lines for time-line graphs are not labelled on graph. To include labels on graph requires the use of another plot program having this capability. Prior to using plot software, test results must be output to a file using the tabular option of the SeeSTAT software. By either editing data using word-processor software or writing a program to reformat data, SeeSTAT output can be tailored to meet the read format of the plot software.

1. Number of samples used to compute moving averages for withintest coefficient of variation is not displayed on column headings for tabular results or curve labels for time-line graphs. 
m. The label "air entrainment" should be changed to "air content" for data entry menu, selection menus, tabular output (column heading), and time-line graphs (curve identifier).

22. Program is being changed to remedy or correct limitations a, b, c, $f$, $i$, and $m$, above. The ACI 214 summary is being changed to include analysis for any age, and the number of curves per graph is being increased to six. Program is scheduled to be changed at a later time to resolve limitations $\mathrm{g}$, $h$, and 1. Program changes to remedy limitations $d, e$, and $k$ are being investigated. No program change is presently scheduled for limitation $j$. 


\section{PART VI: CONCLUSIONS AND RECOMMENDATIONS}

23. The SeeSTAT program meets the Corps of Engineers software needs for storing, computing, and reporting of concrete test data generated during a construction project. Menu-driven search routines provide easy retrieval of data. Tabular and time-line options provide increased capabilities for evaluating test results and, thereby, the potential for earlier detection of batching and testing problems. Frequency distribution analysis gives an indication of how well the data fit a normal distribution curve. The regression analysis defines the relationship between sets of results and provides prediction capabilities.

24. Tabular reports are output to disk file in ASCII (text) format, which allows for word processing and electronic mailing. Results can be tailored to make easier periodic reporting and to prepare a summary of concrete test results for the concrete report (report is required for all major and all unique Civil Works construction projects [ER 1110-2-402]). Detailed tabular results can be stored on diskettes for enclosure with concrete report and for retention at project site as a part of the permanent collection of project data required by Appendix A of ER 1110-2-100.

25. It is recommended that the SeeSTAT software be considered for use Corps-wide. Because of the potential benefit to future concrete construction, repair, and research efforts, it is also recommended that, at projects where SeeSTAT is employed, diskettes containing concrete test results and SeeSTAT data files accompany the distribution of the concrete report. Results should include data for all mixtures and samples. Two tables per mixture should be generated using Tables 1 and 2 as guides.

26. For future reference, the U.S. Army Construction Engineering Research Laboratory (CERL) is developing for Corps-wide use a software program that includes analysis of concrete strength test results. Inquires regarding this software can be made to:

Commander and Director

U.S. Army Construction Engineering

Research Laboratory

ATTN: Debbie Lawrence

P.0. Box 4005

Champaign, IL 61820-1350 


\section{REFERENCES}

American Concrete Institute Committee 214-77 (Reapproved 1988). "Recommended Practice for Evaluation of Strength Test Results of Concrete," Detroit, MI.

Campbe11, R. L. 1982. "Computer-Aided Analysis of Concrete Strength Test Results," Instruction Report SL-83-1, US Army Engineer Waterways Experiment Station, Vicksburg, MS.

Department of the Army. 1988. "Periodic Inspection and Continuing Evaluation of Completed Civil Works Structures," Engineer Regulation 1110-2-100, Washington, DC.

Office of the Chief of Engineers, Department of the Army. 1980. "Engineering and Design Concrete Reports," Engineer Regulation 1110-2-402, Washington, DC. 


\section{WATERWAYS EXPERIMENT STATION REPORTS PUBLISHED UNDER THE COMPUTER APPLICATIONS IN GEOTECHNICAL ENGINEERING (CAGE) PROJECT}

Title

Date

Miscellaneous Paper GL-79-19 Results of Geotechnical Computer Usage Survey

Aug 1979

Miscellaneous Paper GL-82-1 Geotechnical Computer Program Survey

Mar 1982

Instruction Report GL-83-1

Geotechnical Construction Control Data Base System

Apr 1983

Instruction Report GL-84-1

Boring Information and Subsurface Data Base Package, User's Guide

Sep 1984

Miscellaneous Paper GL-85-8

Criteria for Limit Equilibrium Slope-Stability Program Package

May 1985

Instruction Report GL-85-1

Microcomputer Boring and Subsurface Data Package, User's Guide

Sep 1985

Instruction Report GL-85-2 Piezometer Data Base Package, User's Guide

Oct 1985

Instruction Report GL-87-1

User's Guide: UTEXAS2 Slope-Stability Package; Volume I, User's Manual

Jul 1987

Miscellaneous Paper GL-87-25 An Examination of Slope Stability Computation Procedures for Sudden Drawdown

Sep 1987

Instruction Report GL-87-1

User's Guide: UTEXAS2 Slope-Stability Package; Volume II, Theory

Feb 1989

Miscellaneous Paper SL-91-2 Evaluation of a Software Program for Storing, Computing, and

Mar 1991 Reporting Concrete Test Results 